\title{
Competitive Research Grants and Their Impact on Career Performance
}

\author{
Carter Bloch • Ebbe Krogh Graversen • \\ Heidi Skovgaard Pedersen
}

Published online: 31 January 2014

(C) Springer Science+Business Media Dordrecht 2014

\begin{abstract}
The role of competitive funds as a source of funding for academic research has increased in many countries. For the individual researcher, the receipt of a grant can influence both scientific production and career paths. This paper focuses on the importance of the receipt of a research grant for researchers' academic career paths utilizing a mixed methods approach that combines econometric analysis with in-depth qualitative interviews. The analysis has novel elements both in terms of its subject (impact of funding grants on individuals' academic career paths) and approach. The results of this study indicate that while research grants have a positive impact on the research performed under the grant itself, there are very important secondary effects on research performance through positive effects on academic career advancement. The probability of obtaining a full professorship for grant recipients is almost double that for rejected applicants, 16 percent compared to 9 percent. The probability for career advancement in general is about 9 percentage points higher for grant recipients. Qualitative interviews support these quantitative results by providing insights into how grants impact research careers, through heightened status, recognition, networking and other factors.
\end{abstract}

Keywords Academic career paths - Research grants - Propensity score matching · Impact · Treatment effects

\section{Introduction}

The role of competitive funds as a source of funding for academic research has increased in many countries. A number of studies have examined the use of

C. Bloch $(\bowtie) \cdot$ E. K. Graversen · H. S. Pedersen

Department of Political Science and Government, The Danish Centre for Studies in Research and

Research Policy, School of Business and Social Sciences, Aarhus University, Bartholins Allé 7,

8000 Aarhus C, Denmark

e-mail: carter.bloch@cfa.au.dk 
performance-based funding in allocating public funding across departments and universities, and its impact on education and scientific production (see e.g. Auranen and Nieminen 2010; Liefner 2003; Geuna and Martin 2003; Larsen 2011). The overall rationale for an increased reliance on competitive funding is that competitive financing mechanisms will funnel resources to those researchers and universities that are most qualified, with subsequent improvements in performance within both research and education. There are, however, a number of issues related to competitive funding as an allocation mechanism, and studies have identified both positive and negative consequences of changes in funding structures, e.g. Benner and Sandström (2000), Bolli and Somogyi (2011), Defazio et al. (2009), Jacob and Lefgren (2011) and Lissoni et al. (2011) among others.

At the individual level, the receipt of a grant can influence both scientific production and career paths of researchers. The ultimate goal of research grants is to promote state of the art research; however, grants may impact research through a number of intermediate channels, by enhancing interaction, knowledge transfer and research and by improving research management competencies. In terms of academic careers, research grants may improve chances for academic advancement, collaboration and other academic activities; all of which may impact research performance due to improved academic skills and status.

At a more aggregated level, it is important to determine the impact of funding on research and research productivity and to create an efficient incentive system for researchers. In the EU, for example, recent policy plans have been launched to create a world leading research environment and attract top international researchers. The present analysis can be seen as a first step in examining whether external funding of research projects may benefit researchers' career development and thereby secure a prominent and attractive national research system with opportunities for academic advancement. Academic career advancement can, drawing, for example, on the analysis of qualitative interviews with grant recipients, be seen as an overall measure of a number of impacts on research performance. ${ }^{1}$ Hence, it is important also from a research policy point of view to know whether certain funding measures can support a positive research system more than others.

This paper examines the importance of research grants for researchers' academic career paths. The analysis is based on data for applications and awards of grants to independent research projects in Denmark over the period 2001-2007. ${ }^{2}$ The Danish Council for Independent Research supports research activities based on the researchers' own initiatives and under free competition. The research council allocates grants with the purpose of enhancing the quality and internationalization of Danish research. The Council has five disciplinary sub-councils to which the researchers submit their research proposals. A key instrument of the Council, and the object of this analysis, is grants towards research projects. The grants are open to

\footnotetext{
1 E.g. Langberg et al. (2004) and Graversen (2004).

2 The analysis builds on a mixed methods evaluation of research grant based projects of the Danish Council for Independent Research, which was conducted by CFA on behalf of the Danish Agency for Science, Technology and Innovation. See Bloch et al. (2011).
} 
all researchers in Denmark ${ }^{3}$ and are awarded based on a peer review process within all fields of sciences. The grants vary in size from under 50,000 to over 1 million Euros. The average amount awarded for 2001-2007 was around 161,000 Euros. In 2007, 614 million DKK (82 million Euros) ${ }^{4}$ were awarded to small and large research projects, accounting for 60 percent of total funding from the Council in that year. There is a high level of competition for the grants, which has increased over the analysis period. Success rates for research project applications range from 28 percent in 2001 to 33 percent in 2004 and down to 24 percent in 2007.

The analysis has two objectives. The first is to perform a quantitative analysis of the impact of grant receipt on academic career advancement. The second is to gain an overall qualitative picture of the importance of research project grants for academic careers. The quantitative analysis uses propensity score matching procedures to examine whether receipt of a grant has an effect on career advancement. Grant recipients are compared with a group of rejected applicants that are comparable to the grant recipients based on a number of characteristics. We then test whether grant recipients have a greater probability of obtaining a tenured position or becoming a full professor three years after the grant has been awarded. The qualitative study is based on semi-structured interviews with a random sample of 20 grant recipients over the period, where interviewees are asked concerning a variety of potential impacts of the research grant, such as their career, research, collaboration and teaching. The combination of these two methods yields a richer and more informative analysis. The quantitative analysis provides objective and robust evidence on the effect of grants on career advancement while the interviews serve both to validate the quantitative results and to complement them by examining how and why grants impact career paths.

The analysis has novel elements both in terms of its subject (impact of funding grants on academic career paths) and approach. While some quantitative analyses on the effects of research grants on research publications exist, almost no attention has been given to the impact on career advancement. The quantitative methods used in this present analysis have not been previously applied in the context of academic funding and career paths, which is often based solely on qualitative assessments or simple statistical comparisons. Propensity score matching provides a sounder basis for assessing the relation between academic funding and career paths. The qualitative analysis provides insight on how grants may impact career paths. Research results from the funded project are important here, but as we will see below, more qualitative effects such as increased status and recognition are cited as very important parts of overall funding effects. Combined with the deeper insight from the qualitative analysis, the results thus contribute to understanding of the role of competitive funding on research, careers and education, and add to knowledge on the factors affecting academic success and career paths, which are important for higher education management.

\footnotetext{
${ }^{3}$ Foreign or Danish researchers abroad can also receive grants if their proposed research clearly benefits Danish research.

${ }^{4}$ The exchange rate between DKK and Euro is 7.45. (1 Euro=7.45 DKK).
} 
The results of this study thus indicate that while research grants may also have a positive impact on the research performed under the grant itself, there are very important secondary effects on research performance through positive effects on researcher status and recognition. Interviewed grant recipients cite the central role of grants in facilitating subsequent collaborations with leading researchers in their field and in establishing their own positions in research communities. Potential indirect effects on research performance through strengthened status and recognition are possibly greater than direct effects based on the outcomes of grant projects themselves. The quantitative analysis provides strong evidence on the role of research grants in strengthening researchers' career positions, thus supporting the insights from interviews. We find that the receipt of grants from the Danish Council for Independent Research leads to positive and statistically significant increases in the probabilities of career advancement in general and in the probability of attaining a full professorship. The probability of becoming a full professor is almost double for grant recipients, 16 percent compared to 9 percent. The probability for career advancement (either from a non-tenured to a tenured position, or from associate to full professor) is about 9 percentage points higher for grant recipients.

The remainder of the paper is organized as follows. The next section reviews related literature concerning both public research funding and the determinants of academic career progression. Subsequently, we describe the quantitative and qualitative methods used in the analysis, and then present the data and results of the analysis. The final section concludes on the findings from the mixed methods based analysis.

\section{Literature Review}

There are a number of analyses of the impacts of different types of external funding on individual research performance. However, these typically examine effects on publications and, to a lesser extent, on collaboration. Jacob and Lefgren (2011) estimate the impact of receiving US National Institute of Health postdoctoral and research grants on subsequent publications and citations. They find evidence of a limited, positive impact, which they argue may be explained by researchers' access to other funding sources. Carayol and Matt (2006) investigate publication intensities at a French university. They only find evidence of public contractual funding affecting the publication intensity and that the intensity and quality of colleagues' research activities are beneficial for individual research.

Another measure of productivity which emerges within the literature is the effect of collaboration on individual publications. Lee and Bozeman (2005) find that collaborative work is the main predictor of individual productivity (in the form of publications); both of fractional and total counts. Lee and Bozeman (2005) find evidence that collaboration has a significant effect on total counts of publications; however, the net effects of collaboration are less clear since the effect on 'fractional counts' of publications is insignificant. They also find a significant effect of receiving a grant on publications. Gaughan and Bozeman (2002) find that obtaining a public grant enhances academic productivity whereas a private grant does not. 
Defazio et al. (2009) investigate funding incentives, collaboration and scientific publications from the EU framework program, and find evidence that funding of collaborative projects has a generally positive effect on publications. Lissoni et al. (2011) find that size and international nature of collaborative projects have significant effects on productivity; moreover, productivity is also an important determinant of career advancement.

The literature on how collaboration affects citations is investigated by, for example, Katz and Hicks (1997) who find evidence that collaboration increases citations and that 'many authors - many countries' collaborations affect the citation rate most. Further, they find that the average citation per paper varies according to field of science. Glänzel $(2001,2002)$ further supports that international coauthorship increases citations, but also finds that extensive collaboration does not result in further increases in productivity and that international collaboration does not necessarily result in higher visibility, i.e. the effect varies largely among fields. Faber et al. (2010) and Bloch et al. (2011) include bibliometric analyses of citations of Danish researchers. Both studies find a significant effect of grants on citation rates, indicating an increase in productivity due to such funding.

To our knowledge, the only other analysis of the effect of grant funding on career advancement is in Pion (2011). Pion (2011) examines the effect of National Research Service Award (NRSA) pre-doctoral grants on a variety of measures of early career outcomes, among these the acquisition of a tenure-line position and employment at a top-ranked academic institution. Simple comparison of NRSA awardees with Ph.D.s from other institutions found that shares were higher among NRSA awardees for both obtaining a tenure-track position and employment at a topranked academic institution.

Another strand of literature examines the role of different funding mechanisms on research performance, in particular what effect the increasing reliance on competitive funding has had for research performance (e.g. Auranen and Nieminen 2010; Tammi 2009; Benner and Sandström 2000; Liefner 2003; Geuna and Martin 2003). These studies mostly concern the macro-level analysis of science systems whereas there is a lack of information regarding the individual effects of external funding. These studies discuss a number of potential negative effects of competitive grant funding. Among these are: potential self-selective bias in allocation of grants and resulting performance indicators, adverse effects on both teaching and research diversity of concentrating top research capacity in a few institutions, and suboptimal changes in researchers' priorities and activity to meet pre-selective grant determining performance indicators. Bolli and Somogyi (2011) examine the impacts of external funding on research productivity for departments at Swiss universities, where they divide external funding into two categories; private and public. They construct a measure of technology transfer using survey data on the importance of various technology transfer channels, such as informal contacts, technical facilities, education, and research collaboration and consulting. They find that public external funds increase publication productivity but have no effect on technology transfer. Private funding, on the other hand, increases both publication and technology transfer activities. 
There clearly exists a gap within the literature concerning funding's effect on academic career paths, as studies have mainly focused on publications and collaborations. Career effects are an important element in overall effects of grant funding. In addition, analysis of funding effects on careers adds to our understanding of the factors that influence academic career paths.

\section{Qualitative and Quantitative Methodology}

This section outlines the mixed methods design used in the analysis. The quantitative analysis estimates the effect of grants on the probability of career advancement by comparing grant recipients with rejected applicants that are matched according to a range of characteristics. Qualitative interviews seek to validate these results and further complement the picture by examining how and why grants have impacted academic careers. In particular, we examine the following hypotheses:

Hypothesis 1: Funding from the Danish Council of Independent Research advances the academic careers of funded researchers

Hypothesis 2: The Danish Council of Independent Research's funding has a positive effect on the research system's ability to keep prominent researchers by benefitting their career development

The analysis will test whether external funding from the Danish Independent Research Council has an explicit and measurable effect on overall career advancement and/or becoming a full professor. The applied research design enables an analysis where all other influencing factors are controlled for, thus isolating the effect of grants on career outcomes. More broadly, the analysis examines whether the Danish funding system is well-functioning in terms of keeping the best researchers within academic research. In the longer run, maintaining the best researchers secures the quality of future research. This section first describes the qualitative methods used and thereafter the quantitative analysis.

In order to identify the implicit incentive structure in researcher career planning and the influence of external funding therein, the principal investigators of 20 research grant projects were interviewed concerning the importance of the research grants for their research and academic career progression. The structure of interviews and the selection of interviewees were designed in order to facilitate comparison with the quantitative results, and to assess their validity. Among the topics covered in the interviews, grant recipients were asked to provide their overall experience of receiving a grant and how or to what extent the grant impacted their academic career, status in their research environment, publications and other factors. Interviewees were selected randomly according to main field, gender, application year and project size. ${ }^{5}$ Semi-structured interviews were chosen to

\footnotetext{
5 See Degn et al. (2011).
} 
achieve a balance between open responses and a harmonization of interview material to allow better comparison with the quantitative data.

The quantitative analysis seeks to obtain rigorous results on the impact of grants on career advancement. The basic idea behind the quantitative approach is to compare the career outcomes of grant recipients with those of applicants that have not received a grant, but are otherwise comparable according to observable characteristics not influencing the funding decision. The fundamental evaluation problem addressed is the counterfactuals outcome that grant recipients would have experienced in the absence of treatment (the treatment effect). A key issue that needs to be considered is potential selection bias that arises due to underlying differences between grant recipients and rejected applicants. The endogeneity problem is due to the nature of non-experimental data where individuals do not receive grants randomly. Rather, they receive grants due to characteristics that make them eligible for funding, according to the decision rule. To deal with endogeneity issues in estimating the career effect of receiving funding, the research design needs to account for potential differences between grant recipients and rejected applicants.

The Differences-in-Differences (DID) approach seeks to estimate treatment effects while eliminating individual time-invariant effects due to the longitudinal dimension of the approach. Blundell and Costa Dias (2000) argue that DID produces reliable results when working with longitudinal data. However, the method neither controls for unobserved temporary individual-specific components nor for differential impacts across the groups of comparison.

Matching seeks to eliminate differences between treatment and control groups by matching them based on observable characteristics, thus ensuring comparability between individuals. Rosenbaum and Rubin (1983) suggest using Propensity Score Matching (PSM) where a set of explanatory variables define the propensity score for each individual. However, it is difficult to conclusively argue that the strict indentifying assumptions for matching are fulfilled (i.e. that treatment and control groups are the same with the exception of the treatment itself). The problem is mainly due to the fact that selection is only on observables, where there often may be unobservable factors that are important.

A third approach is Conditional DID, which combines the previous two approaches, providing scope for differences in unobserved factors as long as they comprise individual and/or time-specific components of the error term (Blundell and Costa Dias 2002). The method has less stringent identifying assumptions compared to either DID or PSM and it eliminates selection on constant observables and unobservables. The combination of the two methods provides more reliable results, as argued by, e.g., Heckman et al. (1998), Dehejia and Wahba (1999; 2002) and Smith and Todd (2005).

We employ a Conditional DID approach to evaluate the effects of external funding on promotion and tenure among Danish researchers. The method is not commonly applied for analyses within higher education. However, some examples can be found within work on the effects of R\&D subsidies for companies (Blundell and Costa Dias 2002; Girma and Görg 2007; Greenaway and Kneller 2008; Czarnitzki et al. 2007; Aerts and Schmidt 2008). 
Table 1 Description of the Nearest-Neighbor Matching procedure used in this paper

1) Specify and estimate a probit model of the probability of receiving a grant to obtain propensity scores $\hat{P}(X)$

$\operatorname{Pr}(Y=1 \mid X)=G\left(\beta_{0}+\beta_{j} X_{j}\right)$

2) Restrict the sample to include only individuals within the common support area (where individuals with the same characteristics have a positive probability of being both treated or non-treated)

3) Each treatment (receipt of grant) is paired with the non-treated that has the closest propensity score. The difference between propensity scores for treatments and matched controls must be within 0.001 ; otherwise they are excluded from the sample, thus eliminating poor matches. Moreover, matching is performed with replacement; i.e. non-treated are not removed after they are matched with a treated individual. Matching without replacement is affected by the sort order and due to the sample size we wish to avoid this

4) Applying the matched sample, the average treatment effect on the treated is estimated by a DID setup. We apply a probit model due to binary dependent variables; the dependent variable is measured by the difference in the outcome variable between pre-treatment and post-treatment

5) As matching with replacement biases the t-statistics, we correct the standard errors for the appearance of repeated observations by bootstrapping (Lechner 2002)

Girma and Görg (2007) employ a Conditional DID approach to evaluate foreign ownership wage premiums. A probit model estimates the probability of "being treated," and DID estimation is based on the matched sample of individuals following the approach suggested in Blundell and Costa Dias (2002). The approach is based on longitudinal data and includes explanatory variables that control for temporary individual-specific components. This approach is also applied by Greenaway and Kneller (2008) who analyze spillover effects of globalization on a sample of UK firms. Czarnitzki et al. (2007) investigate the relationship between $R \& D$ collaboration, subsidies and $R \& D$ performance by a similar approach. The mentioned papers all use binary indicators evaluated by Ordinary Least Squares, which, however, ignores the limitations of using linear models in assessing probabilities.

In this paper we apply a similar approach. The main difference is that we apply a non-linear model in estimating the effect, due to the dependent variable being binary. Moreover, we include additional explanatory variables in the outcome model to control for time-variant effects and thereby reduce heterogeneity among grant recipients and rejected applicants. The specific propensity score matching approach we employ in this analysis, Nearest-Neighbor Matching, is described in Table 1.

The impact of grant receipt is measured as the Average Treatment Effect of the Treated, ATT, which is the difference in probability of 1) career advancement to a higher academic position or 2) becoming a full professor between grant recipients (treated) and matched rejected applicants (untreated) three years after the grant application. As an additional test of robustness, we condition treatment effects on a number of other factors that may affect career progression through the estimation of a probit model based on the matched sample. As noted above, the Conditional DID estimation includes both the variables included in the matching procedure, a variable for receiving a grant (treatment variable), and additional variables that may 
influence the treatment effect. The dataset used in the analysis and construction of variables are described in the next section.

\section{Data}

The quantitative analysis here uses individual data on all applicants for research grants from the Danish Agency for Science, Technology and Innovation's funding database merged with data on employment and academic position on all university researchers from the Danish State Employers' Authority, and register data from Statistics Denmark. The funding data covers applications and grants for research projects for the period 2001-07, while data on place of employment, occupation and educational background covers the period from 2001-10. The gross population of applicants over the period 2001-2007 is 3,027.

Data on employment includes all occupations in central government (which includes universities). Hence, the data provides information on all researchers' career status as long as they are at a university. Statistical register data contains additional information on individuals, including demographics, work and educational characteristics.

Hence, based on the merged register data, we are only able to observe individuals that are still employed in the public research sector in Denmark. We were thus unable to include researchers that were not employed in a Danish public research institution three years after the grant application. Of the total of 3,027 applicants, data on academic position was missing for 599 individuals, 170 grant recipients and 429 rejected applicants. The most likely explanations for the missing data are that the individuals were out of the country for the years in question, or they had left the university sector. An additional 23 were also removed from the sample as they had either died or retired within three years of grant application.

Researchers are grouped into four categories for academic positions: full professors, associate professors, assistant professors and post-doctoral researchers. Full professors and associate professors are tenured (permanent) positions. Furthermore, there is no mandatory retirement age for academic researchers. Assistant professorships in Denmark are three year positions that cannot be extended, thus career advancement is required if the researcher stays at the same research institution; otherwise the researcher may apply for assistant professor positions at other research institutions or departments. Post-docs are typically 1-2 year positions that can be extended and are thus more flexible from the employer's viewpoint. Post-docs and assistant professorships are considered to be at the same level in terms of a non-tenured academic position.

As we are analyzing the effect on academic career advancement, we do not include researchers who held a full professorship at the time of application, since they cannot advance to a higher academic professor position. Including them in an analysis of the probability of career advancement or of becoming a full professor would result in upwards bias of the results, since they were a full professor prior to receiving the grant. 638 applicants were full professors at the time of application. Finally, 80 applicants in the sample were either $\mathrm{PhD}$ students or research assistants 
and did not hold one of the four academic positions at the time of application. Given that this group lacked basic research qualifications at the time of application, they were removed from the sample. The final sample used in the analysis is thus 1,687 observations.

As recommended by Caliendo and Kopeinig (2008), we include variables that are reasonable for the analysis. Further, the specification is evaluated on the basis of the matching quality. In order to ensure comparability between grant recipients and rejected applicants, the matched sample should be balanced (not significantly different from each other) according to all specified matching variables. The variables included in the probit model account for research experience, field of science, academic position at time of application, application year, age and whether the individual had previously received a grant prior to the period of analysis.

Years since $P h D$ is a grouped variable divided into 3 subgroups; under 4 years, 4 to 8 years and 9 or more years. We also include Age to control for an expected decreasing effect after controlling for experience. The reason for using categories for Years since $P h D$ is to reduce correlation with the age variable and also to better facilitate a more balanced matching procedure. These categories reduce dimensionality while at the same time ensuring that we are comparing researchers at the same stage of their careers and in the same age group. Dummy variables are used for five fields of science that also correspond to the individual research councils: Natural Sciences, Medical Sciences, Technology and Production Sciences, Social Sciences and Humanities. Academic position is included as dummy variable for each of the four positions. Granted before is a dummy variable that indicates whether the researcher has received any form of grant from the Council prior to the period analyzed here (i.e. before 2001). Additional variables are a dummy variable for whether the researcher is married (or has a registered partner), Relationship, and a dummy if the researcher has worked abroad, Foreign network.

Table 2 below shows a number of descriptive statistics for awardees and rejected applicants over the period 2001-2007. ${ }^{6}$ In each case, statistics refer only to the principal investigator for the research grant.

Note first that the shares of grant recipients that achieve a full professorship or career advancement in general are significantly higher than for rejected applicants. While this suggests that grants have a positive impact on career advancement, we cannot see from the table to what extent the difference is due to differences in the two groups prior to application as opposed to a grant effect. Average age for the two groups is almost equal, as is the gender distribution. However, the group of grant recipients has a larger number of associate professors and there are significant differences in the distribution according to field of science and application year. The underlying pre-application differences between grant recipients and rejected applicants emphasize the need for a matched sample that consists of comparable researchers in order to better isolate the effects of grant receipt. The next section presents the results of the matching analysis.

\footnotetext{
${ }^{6}$ A number of researchers may have applied for grants more than once during the period. For grant recipients, the statistics refer to the first research grant that they have received during the period. Rejected applicants have not received a grant during the entire period, and in line with grant recipients, the statistics refer to the first application in the period.
} 


\section{Analysis}

This section presents the results of the analysis. We first describe the quantitative analysis and then discuss the qualitative results and how they contribute to characterizing the effects of grants on career advancement.

\section{Propensity Score Matching}

The matched sample is determined using the PSM procedure outlined in section "Qualitative and Quantitative Methodology." First, a probit model is estimated for the probability of grant receipt. Table 3 shows that years since $\mathrm{PhD}$, year of application, earlier grants and age are important determinants of receiving a grant.

Table 2 Descriptive statistics for the sample of post-docs, assistant and associate professors at time of application

\begin{tabular}{|c|c|c|c|c|}
\hline \multirow[t]{2}{*}{ Variable } & \multicolumn{2}{|c|}{ Rejected applicants } & \multicolumn{2}{|c|}{ Granted recipients } \\
\hline & Mean & $\begin{array}{l}\text { Standard } \\
\text { error }\end{array}$ & Mean & $\begin{array}{l}\text { Standard } \\
\text { error }\end{array}$ \\
\hline Career level advancement 3 years after application & 0.179 & $(0.012)$ & $0.235 * * *$ & $(0.016)$ \\
\hline Full professorship 3 years after application & 0.069 & $(0.008)$ & $0.163 * * *$ & $(0.014)$ \\
\hline Age & 48.5 & $(0.278)$ & 48.4 & $(0.303)$ \\
\hline Female & 0.253 & $(0.014)$ & 0.250 & $(0.016)$ \\
\hline \multicolumn{5}{|l|}{ Application year } \\
\hline 2001 & 0.134 & $(0.011)$ & 0.144 & $(0.013)$ \\
\hline 2002 & 0.142 & $(0.011)$ & $0.180 * *$ & $(0.014)$ \\
\hline 2003 & 0.140 & $(0.011)$ & $0.175 * *$ & $(0.014)$ \\
\hline 2004 & 0.143 & $(0.011)$ & $0.175^{*}$ & $(0.014)$ \\
\hline 2005 & 0.153 & $(0.012)$ & 0.133 & $(0.013)$ \\
\hline 2006 & 0.159 & $(0.012)$ & $0.102 * * *$ & $(0.011)$ \\
\hline 2007 & 0.129 & $(0.011)$ & $0.091 * * *$ & $(0.011)$ \\
\hline \multicolumn{5}{|l|}{ Occupation at time of application } \\
\hline Post-doc & 0.037 & $(0.006)$ & 0.030 & $(0.006)$ \\
\hline Assistant professor & 0.201 & $(0.013)$ & $0.112 * * *$ & $(0.012)$ \\
\hline Associate professor & 0.761 & $(0.014)$ & $0.858 * * *$ & $(0.013)$ \\
\hline \multicolumn{5}{|l|}{ Field of Science } \\
\hline Natural Sciences & 0.125 & $(0.017)$ & $0.290 * * *$ & $(0.010)$ \\
\hline Medical Sciences & 0.189 & $(0.013)$ & $0.267 * * *$ & $(0.016)$ \\
\hline Production and Technology Sciences & 0.369 & $(0.016)$ & $0.196 * * *$ & $(0.015)$ \\
\hline Social Sciences & 0.163 & $(0.012)$ & $0.122 * * *$ & $(0.012)$ \\
\hline Humanities & 0.155 & $(0.012)$ & $0.126^{*}$ & $(0.012)$ \\
\hline Number of observations & & 963 & & 724 \\
\hline
\end{tabular}

*** (**,*) Indicates that the differences in means for grant recipients and rejected applicants are significant at the $1 \%(5 \%, 10 \%)$ level; standard errors are denoted in parentheses 
Table 3 Marginal effects of the likelihood of grant approval

\begin{tabular}{lll}
\hline & Marginal effects & Standard error \\
\hline Years since PhD & $0.025^{* *}$ & -0.011 \\
Medical Sciences & $-0.074 *$ & -0.038 \\
Production and Technology Sciences & $-0.322^{* * *}$ & -0.031 \\
Social Sciences & $-0.204 * * *$ & -0.037 \\
Humanities & $-0.195 * * *$ & -0.037 \\
Application year & $-0.021 * * *$ & -0.007 \\
Post-doc & -0.054 & -0.067 \\
Assistant Professor & $-0.190 * * *$ & -0.034 \\
Age & $-0.009 * * *$ & -0.002 \\
Grants before sample period & $0.164 * * *$ & -0.026 \\
Log-likelihood & -1042 & \\
Pseudo R & 0.096 & \\
Number of observations & 1687 & \\
\hline
\end{tabular}

*** $(* *, *)$ Significant at $1 \%(5 \%, 10 \%)$; Standard errors are denoted in parentheses. Reference groups are Natural Sciences with respect to field and Associate Professor with respect to academic position

Further, the likelihood of receiving a grant is higher for researchers from the Natural Sciences compared to the other fields of science.

Age is negatively related to the likelihood of receiving funding after controlling for experience, thus older researchers have lower probabilities of funding compared to younger researchers with the same experience. Moreover, there is a decreasing likelihood of receiving funding during the observed period. This is due to an increasing number of researchers competing for available funding, and increases in average grant size. Over the period, success rates have fallen from 28 percent in 2001 to 24 percent in 2007, while average grant size has increased from 131,000 to 241,000 Euros. And, having received funding earlier (before 2001) increases the probability of obtaining funding during the sample period.

Assistant professors have lower probabilities of receiving funding compared to associate professors. Post-docs also have a lower estimated likelihood of being funded, but this difference is not statistically significant. According to the data, postdocs are more experienced in their search for external funding than assistant professors, which may be the underlying reason for the differences among these two groups that are essentially at the same career level.

The grant propensity model in Table 3 does not control for gender, though the impact of gender is analyzed in the analysis of marginal effects of grant receipt shown in Table 6. The reason for this is that gender was not found to affect the propensity of receiving a grant. However, gender may very well influence the subsequent effect of receiving a grant. As can be seen in Table 6 below, women have a significantly higher probability of career advancement in the matched sample.

The propensity score is calculated on the basis of the probit model. Researchers are matched according to the variables in the estimation, as shown in Table 3 . The area of common support ranges from 0.095 to 0.868 . 142 individuals are outside of 
the common support, which means that they either have an extremely low or extremely high estimated probability of receiving a grant, in either case making them very poor candidates for inclusion in the matching analysis. For this reason, observations outside of the common support are removed, thus resulting in a sample of 1,545 researchers. The matched sample consists of 582 researchers that received funding and 963 rejected applicants; this implies that there are granted researchers who could not be matched with rejected applicants at both the lower and upper levels of the propensity score, according to the common support area. Due to the matching protocol we match researchers with the closest propensity score, thus not all rejected applicants within common support are used in evaluating the treatment effect. 369 rejected applicants and 582 grant recipients are used to evaluate the average treatment effect on the treated (ATT). Due to our matching approach with replacement, rejected applicants that are matched with several granted researchers are weighted in accordance with the number of granted researchers they are matched to. In total, the sample on which the ATT measure is estimated consists of 951 researchers.

Table 4 shows the means of the matching variables for both the full (unmatched) and matched sample. This provides a test of the quality of the matching procedure, whether grant recipients and rejected applicants are comparable (based on the matching variables) in the matched sample. As Table 4 shows, the sample does not display systematic differences among grant recipients and rejected applicants after matching. According to t-tests, there is no difference between treatments and controls. Matching has in particular corrected for differences in field, application year and earlier grant reception.

\section{Grant Effects on Career Advancement}

Table 5 shows the estimated treatment effects of receiving a research grant based on the matched sample. The table shows first the shares of grant recipients and rejected applicants that have attained a full professorship or career advancement in general three years after grant application, and thereafter the difference between the two (ATT). The ATT measure is the main result of the analysis. The difference in probabilities between grant recipients and rejected applicants is the measure of the effect of research grants on career advancement. The likelihood of career advancement for grant recipients is 8.8 percentage points higher than matched applicants which did not receive a grant. Results concerning full professorship are similar, with the likelihood of becoming a full professor 7.2 percentage points higher for grant recipients. Both these results are highly significant, indicating that receipt of a research grant has a positive effect on both the probability of obtaining a full professorship and of career advancement in general.

We have also examined whether the results are sensitive to the specification of the model, by varying the inclusion of characteristics. Changes in the specification of the probit model show little variation in the ATT, thus suggesting that the estimated treatment effects are rather robust towards specification. 
Table 4 Means of the matching variables before and after matching

\begin{tabular}{|c|c|c|c|c|c|}
\hline Variable & Sample & $\begin{array}{l}\text { Grant } \\
\text { recipients }\end{array}$ & $\begin{array}{l}\text { Rejected } \\
\text { applicants }\end{array}$ & t Statistics & $P$ value \\
\hline \multirow[t]{2}{*}{ Propensity score } & Unmatched & 0.501 & 0.376 & 15.560 & 0.000 \\
\hline & Matched & 0.454 & 0.454 & 0.000 & 0.996 \\
\hline \multirow[t]{2}{*}{ Years since $\mathrm{PhD}$} & Unmatched & 3.832 & 3.584 & 4.050 & 0.000 \\
\hline & Matched & 3.749 & 3.847 & -1.390 & 0.164 \\
\hline \multirow[t]{2}{*}{ Medical Sciences } & Unmatched & 0.267 & 0.189 & 3.810 & 0.000 \\
\hline & Matched & 0.266 & 0.229 & 1.490 & 0.135 \\
\hline \multirow[t]{2}{*}{ Production and Technology Sciences } & Unmatched & 0.196 & 0.369 & -7.830 & 0.000 \\
\hline & Matched & 0.242 & 0.244 & -0.070 & 0.946 \\
\hline \multirow[t]{2}{*}{ Social Sciences } & Unmatched & 0.122 & 0.163 & -2.400 & 0.017 \\
\hline & Matched & 0.146 & 0.139 & 0.340 & 0.738 \\
\hline \multirow[t]{2}{*}{ Humanities } & Unmatched & 0.126 & 0.155 & -1.690 & 0.091 \\
\hline & Matched & 0.146 & 0.151 & -0.250 & 0.805 \\
\hline \multirow[t]{2}{*}{ Application year } & Unmatched & 3.645 & 4.030 & -4.080 & 0.000 \\
\hline & Matched & 3.818 & 3.974 & -1.390 & 0.164 \\
\hline \multirow[t]{2}{*}{ Post-Doc } & Unmatched & 0.030 & 0.037 & -0.780 & 0.435 \\
\hline & Matched & 0.034 & 0.034 & 0.000 & 1.000 \\
\hline \multirow[t]{2}{*}{ Assistant Professor } & Unmatched & 0.112 & 0.201 & -4.960 & 0.000 \\
\hline & Matched & 0.129 & 0.108 & 1.090 & 0.277 \\
\hline \multirow[t]{2}{*}{ Age } & Unmatched & 48.427 & 48.538 & -0.270 & 0.789 \\
\hline & Matched & 48.567 & 49.388 & -1.670 & 0.094 \\
\hline \multirow[t]{2}{*}{ Grants before } & Unmatched & 0.507 & 0.315 & 8.140 & 0.000 \\
\hline & Matched & 0.424 & 0.435 & -0.350 & 0.723 \\
\hline
\end{tabular}

A $P$ value above 0.10 indicates that the difference between grant recipients and rejected applicants is not significant at the $10 \%$ level

Table 5 Average treatment effects on the treated

\begin{tabular}{lllll}
\hline & $\begin{array}{l}\text { Granted } \\
\text { recipients }\end{array}$ & $\begin{array}{l}\text { Rejected } \\
\text { applicants }\end{array}$ & ATT & $\begin{array}{l}\text { Standard } \\
\text { error }\end{array}$ \\
\hline Career Advancement three years after grant application & 0.234 & 0.146 & $0.088^{* *}$ & $(0.035)$ \\
Full professorship three years after grant application & 0.155 & 0.089 & $0.072 * * *$ & $(0.024)$ \\
\hline
\end{tabular}

Based on matched sample. *** (**,*) Significant at $1 \%(5 \%, 10 \%)$

Bootstrapped standard errors are denoted in parentheses

Heckman et al. (1997) and Dehejia and Wahba (1999) note that the treatment effect is highly sensitive to the matching parameters, thus omitted variable bias can be a serious concern. Hence, as outlined above, we also measure treatment effects using Conditional DID. In essence, this involves conducting a probit estimation of career progression based on the matched sample, where we further control for variables that do not influence the probability of funding but may affect the career outcome. 
Table 6 Marginal effects of probit models

\begin{tabular}{|c|c|c|c|c|}
\hline & $\begin{array}{l}\text { Full } \\
\text { professorship }\end{array}$ & $\begin{array}{l}\text { Standard } \\
\text { error }\end{array}$ & $\begin{array}{l}\text { General career } \\
\text { advancement }\end{array}$ & $\begin{array}{l}\text { Standard } \\
\text { error }\end{array}$ \\
\hline Granted & $0.069 * * *$ & $(0.021)$ & $0.086 * * *$ & $(0.026)$ \\
\hline Years since $\mathrm{PhD}$ & 0.013 & $(0.009)$ & 0.015 & $(0.012)$ \\
\hline Age & $-0.003 * *$ & $(0.001)$ & $-0.004 * *$ & $(0.002)$ \\
\hline Foreign network & -0.031 & $(0.025)$ & -0.055 & $(0.032)$ \\
\hline Relationship & $0.044 * *$ & $(0.022)$ & 0.032 & $(0.028)$ \\
\hline Female & $0.067 * * *$ & $(0.020)$ & $0.068 * *$ & $(0.026)$ \\
\hline Medical Sciences & 0.038 & $(0.035)$ & 0.049 & $(0.045)$ \\
\hline Production and Technology Sciences & 0.003 & $(0.034)$ & 0.021 & $(0.045)$ \\
\hline Social Sciences & $0.117 * *$ & $(0.051)$ & $0.180 * * *$ & $(0.061)$ \\
\hline Humanities & 0.010 & $(0.038)$ & 0.012 & $(0.050)$ \\
\hline Application year & $0.012 * *$ & $(0.006)$ & $0.015^{* *}$ & $(0.007)$ \\
\hline Post-doc & $-0.056^{*}$ & $(0.034)$ & 0.031 & $(0.058)$ \\
\hline Assistant Professor & $-0.096 * * *$ & $(0.017)$ & $0.431 * * *$ & $(0.060)$ \\
\hline Log-likelihood & 0.000 & & 0.000 & \\
\hline Pseudo $\mathrm{R}^{2}$ & 0.082 & & 0.1724 & \\
\hline Number of observations & 951 & & 951 & \\
\hline
\end{tabular}

*** (**,*) Significant at 1\% (5\%,10\%); Standard errors are denoted in parentheses. Reference groups are Natural Sciences with respect to field and Associate Professor with respect to academic position

To measure the effect of grants, a dummy variable is included for grant receipt. Other variables include years since $\mathrm{PhD}$, age, foreign network, relationship, gender, field and academic position. Table 6 displays the estimated marginal effects from the probit estimation on career progression, again using the matched sample. First, note that the marginal effects for treatment ("Granted") are positive and significant for both measures of career advancement, and with almost exactly the same coefficients as above in Table 5. This provides strong evidence for the robustness of our results.

Age has a small negative and significant effect on career progression which indicates that, controlling for other factors, older researchers have a slightly smaller probability of career advancement. Women have a higher probability of becoming a full professor in this matched sample and for career advancement in general. Both post-docs and assistant professors have an expected lower probability of becoming full professors than associate professors in the three year period. However, assistant professors have a significantly higher likelihood of career advancement in general compared to associate professors. In contrast, there is no difference in the likelihood of advancement among post-docs and associate professors.

\section{Interviews with Grant Recipients}

Whether career advancement comes directly from the receipt of grants, indirectly through increased publication or via other factors is difficult to determine. 
Qualitative interviews corroborate the quantitative results above and further complement the picture by examining how and why grants have impacted academic careers. $^{7}$ Overall, the interviews indicate that grants, with all their additionalities (publications, research management experience, collaboration, internationalization, teaching etc.) result in career advancement, suggesting that career advancement can be seen as a proxy for the sum of all impacts of grants.

According to the majority of the interviewees, the grants overall have had an important impact on their research possibilities, with regard to publications, collaboration and career progress. About half of the interviewees claim that their research would not have been conducted without the funding from the Danish Council of Independent Research, due to time limitations and lack of funding to support the project from the basic resources of their institution. A number of interviewees argued that it was increasingly difficult to find the time or resources for independent research without external funding. Hence, according to them, the role of grants in facilitating independent research has increased in recent years.

The most emphasized effects of grant funding, more so than impacts on actual research under the grant, was the career and research opportunities that the grants brought. The grants were argued to provide important recognition of their research, validating their research and providing better opportunities to work with top researchers and gain additional funding. As one interviewee states:

"The grant has meant a lot in relation to my career path; both for gaining a full professorship, but also that my status and competencies were lifted upwards within my research field." (Grant recipient within Humanities)

The majority of interviewed grant recipients noted that grants had benefitted them in terms of increased collaboration and stronger networks, both nationally and internationally. Collaborative relationships were strengthened through the work on the grant project; both new and existing relations. Both the financial opportunities that the grant provided and the added attention to their work were important channels here.

"With this type of grant comes a seal of approval that perhaps makes it easier to join a network. The networks one is involved in are of course due to one's own research performance, participation at seminars and conferences and how one is as a collaborative partner. But the grant is still something that functions as a stepping board. In that way it gives a push forwards, career wise." (Grant recipient within Social Sciences)

“...it (the grant) has helped strengthen my position as a researcher, making it easier to secure collaboration partners for research projects and leading to invitations to hold lectures and participate in meetings based on one's own work. So, the grant has meant a great deal and has helped open a lot of doors." (Grant recipient within Medical Sciences)

\footnotetext{
7 This section draws on the analysis in Degn et al. (2011).
} 
Many of the interviewees described the impact of grants in terms of a 'snowball effect'; following funding, researchers have experienced an increased demand to participate in conferences, give presentations of their research and act as peer reviewers. In other words, a central effect of grant funding worked through the increased status and recognition as researchers which in turn gave greater opportunities for undertaking top level research and for career advancement.

As alluded to above, receiving a grant was associated with prestige and recognition which has a positive impact on their research. If an application leads to a grant, it is described as an endorsement of the researcher's research. This means that the grant recipient "moves up in the recognition hierarchy," as one interviewee put it. To have success in obtaining external research funding is seen as increasingly important for universities, and in the scientific community there is an awareness of the fact that the success rate of applicants for Council grants is low (average of $24 \%$ for the period as a whole). Therefore, the applicants who manage to get a grant experience greater respect for their work. One of the interviewees stated: "One's prestige and competencies are highlighted within the research environment. For me it has to a large extent meant that I have gone from a lower level in research on to a higher position in my field. It has meant a lot" (Grant recipient within the Humanities).

All the many positive dimensions of outcomes found in the interviews support the results found in many other case studies that grants have a positive personal impact for researchers. While it is not surprising that interviewees report a positive impact on their careers, it is noteworthy that these were the effects most often emphasized in interviews, much more so than on the actual research results of grant project work. However, perhaps the most valuable insight from the qualitative analysis is that impacts on career advancement stem from a broad range of effects such as status and access to new networks.

\section{Conclusion}

This paper has examined the impact of research grants on career performance for academic researchers. The analysis utilizes data on applicants and grant recipients for independent research projects from the Danish Council for Independent Research over the period 2001-2007. We use a mixed methods approach, combining rigorous quantitative methods with qualitative analysis. The quantitative impact assessment needs to address the counterfactuals problem that we do not know what outcome grant recipients would have had if they had not received the grant. To address this, the quantitative approach uses Propensity Score Matching and Conditional Differences in Differences, which seeks to isolate the effects of research grants by comparing career paths of grant recipients with those of rejected applicants that are matched according to observed characteristics. We examine two outcome measures, obtaining a full professorship and career advancement in general, three years after grant application.

Both when examining the probability of attaining a full professorship or of academic career advancement in general, we find that the receipt of grants from the 
Danish Council for Independent Research leads to positive and statistically significant increases. The probability of becoming a full professor is almost double for grant recipients, 16 percent compared to 9 percent. The probability for career advancement is about 9 percentage points higher for grant recipients.

According to the interviewed grant recipients, the grants have had an important impact on their research, with many interviewees claiming that their research would not have been conducted without the funding from the Council, due to time limitations and lack of funding to support the project from the basic resources of their institution. When discussing how grants have affected their careers, many interviewees emphasized the importance of prestige and recognition, that grants facilitated opportunities that would not otherwise have been possible. For example, interviewees stressed the central role of grants in facilitating subsequent collaborations with leading researchers in their field and in establishing their own positions in research communities.

There are a number of implications of our analysis. First, the analysis suggests that while grants may also be important for the research results themselves, an important channel for supporting subsequent research performance appears to be through strengthening the status and competences of funded researchers. Impacts on researchers and not just the research itself should be thus taken into account in the design and awarding of research funding. This may also suggest that impacts of grants are higher for researchers at a relatively early stage of their careers. These results are also relevant for discussions of grant size and success rates, for example, whether funding should focus on the select few (at the expense of lower success rates) or reduce grant size in order to support a larger number of promising researchers. These results suggest that there may be substantial gains, also for postgrant research, from increasing the number of funded researchers.

Even though the results in our analysis to a large extent depend on the specific empirical grant size and funding allocation criteria, along with the structure of academic positions, the conclusions may very well be applicable to other countries or other funding agencies, in particular given the widespread use of project grants in research funding. While there are some differences in national structures, arguably academic positions are among the most generic in an international context, as is evidenced by a number of international projects that are oriented towards researchers, such as the EU Framework Program, Mobility Patterns and Career Paths of EU Researchers $\left(\mathrm{MORE}^{8}\right),{ }^{9}$ Careers of Doctorate Holders $(\mathrm{CDH})$ and the Integrated Information System on European Researchers (IISER ${ }^{10}$ ). Grant size can also have an influence on results. While there exist many funding programs that award grants of a much larger size than those considered here, there are also many programs that are fairly comparable to those considered here. For example, average award size for the U.S. National Science Fund was around \$160 thousand in 2012. ${ }^{11}$

\footnotetext{
${ }^{8}$ http://www.researchersmobility.eu/.

${ }^{9}$ http://www.oecd.org/innovation/innovationinsciencetechnologyandindustry/oecdunescoinstituteforstatistics eurostatcareersofdoctorateholderscdhproject.htm.

${ }^{10} \mathrm{http} / / /$ ipts.jrc.ec.europa.eu/activities/research-and-innovation/iiser.cfm.

11 http://www.nsf.gov/about/budget/fy2012/pdf/07_fy2012.pdf.
} 
In any case, while grant size might affect the specific size of effects, it is unlikely that it would affect the basic results and conclusions of this paper.

At a more aggregated level, it is important to determine the impact of funding on research and research productivity and to create an efficient incentive system for the researchers. In the EU, for example, recent policy plans have been launched to create a world leading researcher market and attract world leading researchers. As such, the present analysis can be seen as a first step in examining whether external funding of research projects may benefit researchers' career development and thereby secure a prominent and attractive national research system with opportunities for academic advancement.

Acknowledgments We are grateful to Stine T. Faber, Lise Degn and Tine Ravn for their work in conducting and analyzing the qualitative interviews with grant recipients. This paper has also benefited greatly from comments by two anonymous reviewers.

\section{References}

Aerts, Kris, and Tobias Schmidt. 2008. Two for the price of one? Additionality effects of R\&D subsidies: A comparison between Flanders and Germany. Research Policy 37(5): 806-822.

Auranen, Otto, and Mika Nieminen. 2010. University research funding and publication performance-An international comparison. Research Policy 39(6): 822-834.

Benner, Mats, and Ulf Sandström. 2000. Institutionalizing the triple helix: Research funding and norms in the academic system. Research Policy 29(2): 291-301.

Bloch, Carter, Mads P. Sørensen, Tine Ravn, Ebbe K. Graversen, Heidi S. Pedersen, Stine T. Faber, Lise Degn, Peter S. Mortensen, Kaare Aagaard, and Per S. Lauridsen. 2011. An Evaluation of Research Project Grants of the Danish Council for Independent Research, Main report and sub-reports. Copenhagen: Danish Agency for Science, Technology and Innovation. (in Danish).

Blundell, Richard, and Monica Costa Dias. 2000. Evaluation methods for non-experimental data. Fiscal Studies 21(4): 427-468.

Blundell, Richard, and Monica Costa Dias. 2002. Alternative approaches to empirical evaluations in microeconomics. Portuguese Economic Journal 1(2): 91-115.

Bolli, Thomas, and Frank Somogyi. 2011. Do competitively acquired funds induce universities to increase productivity? Research Policy 40: 136-147.

Caliendo, Marco, and Sabine Kopeinig. 2008. Some practical guidance for the implementation of propensity score matching. Journal of Economic Surveys 22(1): 31-72.

Carayol, Nicolas, and Mireille Matt. 2006. Individual and collective determinants of academic scientists' productivity. Information Economics and Policy 18(1): 55-72.

Czarnitzki, Dirk, Bernd Ebersberger, and Andreas Fier. 2007. The relationship between R\&D collaboration, subsidies and R\&D performance: Empirical evidence from Finland and Germany. Journal of Applied Econometrics 22: 1347-1366.

Defazio, Daniela, Andy Lockett, and Mike Wright. 2009. Funding incentives, collaborative dynamics and scientific productivity: Evidence from the EU framework program. Research Policy 38(2): 293-305.

Degn, Lise, Stine T. Faber, and Tine Ravn. 2011. Sub-report 3: Case and interview analysis. Evaluation of Research Project Grants of the Danish Council for Independent Research. Copenhagen: Danish Agency for Science, Technology and Innovation (in Danish).

Dehejia, Rajeev H., and Sadek Wahba. 1999. Casual effects in non-experimental studies: Re-evaluating the evaluation of training programs. Journal of the American Statistical Association 94(448): 1053-1062.

Dehejia, Rajeev H., and Sadek Wahba. 2002. Propensity score-matching for non-experimental studies. The Review of Economics and Statistics 84(1): 151-161.

Faber, Stine T., Ebbe K. Graversen, Sanne Haase, Niels Mejlgaard, Peter S. Mortensen, Karen Siune, Kaare Aagaard, and Per S. Lauridsen. 2010. The Danish Research Council's support of female 
researchers and researchers at an early stage of their career. Copenhagen: Danish Agency for Science, Technology and Innovation. (in Danish).

Gaughan, Monica, and Barry Bozeman. 2002. Using curriculum vitae to compare some impacts of NSF research grants with research center funding. Research Evaluation 11(1): 17-26.

Geuna, Aldo, and Ben Martin. 2003. University research evaluation and funding: An international comparison. Minerva 41(4): 277-304.

Girma, Sourafel, and Holger Görg. 2007. Evaluating the foreign ownership wage premium using a difference-in-differences matching approach. Journal of International Economics 72(1): 97-112.

Glänzel, Wolfgang. 2001. National characteristics in international scientific co-authorship relations. Scientometrics 50(1): 69-115.

Glänzel, Wolfgang. 2002. Co-authorship patterns and trends in the sciences (1980-1998). A bibliometric study with implications for database indexing and search strategies. Library Trends 50(3): 461-473.

Graversen, Ebbe K. 2004. The interplay and interfaces between private firms and public research organisations-Why personnel mobility is an important indicator. Working paper 2004/5. The Danish Centre for Studies in Research and Research Policy, Aarhus University, Aarhus.

Greenaway, David, and Richard Kneller. 2008. Exporting, productivity and agglomeration. European Economic Review 52(5): 919-939.

Heckman, James J., Hidehiko Ichimura, and Petra E. Todd. 1997. Matching as an econometric evaluation estimator: Evidence from evaluating a job training programme. The Review of Economic Studies 64(4): 605-654.

Heckman, James, Hidehiko Ichimura, Jeffrey Smith, and Petra Todd. 1998. Characterizing selection bias using experimental data. Econometrica 66(5): 1017-1098.

Jacob, Brian, and Lars Lefgren. 2011. The impact of research grant funding on scientific productivity. Journal of Public Economics 95(9-10): 1168-1177.

Katz, J. Sylvan, and Diana Hicks. 1997. How much is collaboration worth? A calibrated bibliometric model. Scientometrics 40(3): 541-554.

Langberg, Kamma, Ebbe K. Graversen, and Evanthia K. Schmidt. 2004. Researcher influence, resources and autonomy in different managerial systems within the public research sector in Denmark. International Journal of Knowledge, Culture and Change Management 4: 1577-1587.

Larsen, Maria T. 2011. The implications of academic enterprise for public science: An overview of the empirical evidence. Research Policy 40: 6-19.

Lechner, Michael. 2002. Some practical issues in the evaluation of heterogeneous labour market programmes by matching methods. Journal of the Royal Statistical Society Series A (Statistics in Society) 165(1): 59-82.

Lee, Sooho, and Barry Bozeman. 2005. The impact of research collaboration on scientific productivity. The Social Studies of Science 35(5): 673-702.

Liefner, Ingo. 2003. Funding, resource allocation, and performance in higher education systems. Higher Education 46(4): 469-489.

Lissoni, Francesco, Jacques Mairesse, Fabio Montobbio, and Michele Pezzoni. 2011. Scientific productivity and academic promotion: A study on French and Italian physicists. Industrial and Corporate Change 20(1): 253-294.

Pion, Georgine. 2011. The early career progress of NRSA predoctoral trainees and fellows. NIH Publication Number 00-4900. Bethesda: National Institutes of Health.

Rosenbaum, Paul R., and Donald B. Rubin. 1983. The central role of the propensity score in observational studies for causal effects. Biometrika 70(1): 41-55.

Smith, Jeffrey A., and Petra E. Todd. 2005. Does matching overcome LaLonde's critique of nonexperimental estimators? Journal of Econometrics 125(1-2): 305-353.

Tammi, Timo. 2009. The competitive funding of university research: The case of Finnish science universities. Higher Education 57(5): 657-679. 